in Europe and in America comes from another recent study, which showed that the prevalence of cardiac pain was twice as high among men in Marion Country, West Virginia, as in Stavely, Derbyshire. ${ }^{8}$

The evidence that physical inertia at work is important has been growing through the years, ${ }^{9-12}$ and to this have been added studies which indicate that physical inertia during leisure hours is also important. ${ }^{1314}$ It does not require elaborate epidemiological research to show that there is a close interrelationship between physical inertia, body bulk, and consumption of food, so that these secondary risk factors must act through the three important primary risk factorsage, blood pressure, and serum cholesterol-the three which apparently can effectively be used to determine who will get a coronary attack. This case has already been argued. ${ }^{3} 15$

But what Keys and his group are now suggesting is that after 30 years of concentrated effort on both sides of the Atlantic there is still another primary risk factor to coronary heart disease which has gone undetected. On this point further evidence is needed, but the practical importance of their work is incontestable. If the studies which are at present underway are successful in showing that the incidence of coronary attacks can be reduced by programmes which control blood pressure and serum lipid levels, we shall want to identify the high-risk individuals as accurately as we can.

${ }^{1}$ MacMahon, B., and Pugh, T. F., Epidemiology: Principles and Methods. Boston, Mass., Little, Brown and Company, 1970.

2 Cornfield, J., Federation Proceedings, 1962, 21, 58.

3 Morris, J. N., Kagan, A., Pattison, D. C., Gardner, M. J., and Raffle, P. A. B., Lancet, 1966, 2, 553.

4 Fisher, R. A., Annals of Eugenics, 1936, 7, 179.

5 Truett, J., Cornfield, J., and Kannell, W., Fournal of Chronic Diseases, $1967,20,511$.

- Keys, A., et al., Circulation, 1972, 45, 815.

7 Grogono, A. W., British Medical fournal, 1973, 1, 381.

8 Grogono, A. W., British Medical fournal, 1973, 1, 381.

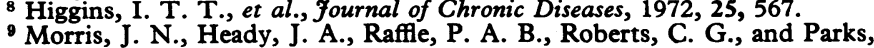
J. W., Lancet, 1953, 2, 1053.

10 Taylor, H. L., et al., American Fournal of Public Health, 1962, 52, 1697.

11 Kahn, H. A., American fournal of Public Health, 1963, 53, 1058.

12 Paffenbarger, R. S., Gima, A. S., Laughlin, M. E., and Black, R. A., American fournal of Public Health, 1971, 61, 1362.

13 Paffenbarger, R. S., Wolf, P. A., Notkin, J., and Thorne, M. C., American Fournal of Epidemiology, 1966, 83, 314.

14 Morris, J. N., et al., Lancet, 1973, 1, 333.

15 Acheson, R. M., Yale Fournal of Biology and Medicine, 1962, 35, 143.

\section{The Medical Society of London}

Founded in 1773, the Medical Society of London celebrates its 200th Anniversary this month. Its founder, Dr. John Coakley Lettsom, F.R.S. (see also page 431), was born in the West Indies - said to be one of seven pairs of twins-in 1744 , and practised as a highly successful London physician during a time when there were bitter rivalries and strife in the medical world and appalling conditions among the sick poor. The state of the prisons and the lunatic asylums gave evidence of the deplorable standard of health, nutrition, and hygiene of the people in the cities. There was little cooperation-often not even association-between the apothecaries, surgeons, and physicians, and large numbers of untrained and uneducated people carried on a lucrative trade as "empirics" or quacks. There was little chance for even the trained doctor to learn new methods or hear of work done in other countries.

To try to overcome some of these defects Lettsom, then still only 29 , founded a society with the purpose of uniting the three branches of the profession so that they could meet in their own house, exchange medical news, find a library of books to read, make friendships, and "advance science." At first he called his society "The Society in Crane Court," and its members met in taverns- 30 physicians, 30 apothecaries, and 30 surgeons. Later he presented the Society with its own building, No. 3 Bolt Court, off Fleet Street. There it held its fortnightly meetings, in the same Court as the Royal Society, until 1850, when it moved-as fashionable society was moving-out of the city to the West End, finally settling in its present building, Lettsom House, 11 Chandos Street, in 1873. It was the first "mixed" medical society to be formed in England, though there had been medical societies in Edinburgh since 1731, and the Physical Society at Guy's Hospital had begun in 1771 .

For 200 years the Medical Society of London has kept an unbroken record of regular lectures and discussions on every aspect of medicine and surgery and has avoided any specialization. Its list of past presidents and orators is an impressive one, and includes distinguished leaders in many fields of medicine. One of its earliest Fellows was Edward Jenner, and the second lecture given to the society by Lettsom was "In Defence of Vaccination."

It was through Lettsom's friendship with Dr. Benjamin Waterhouse, professor of medicine at the newly founded Harvard Medical School, that supplies of vaccine were sent to North America, where Jefferson supported its general acceptance, and it was adopted throughout the country. It was another close friend of Lettsom's, a Quaker from the West Indies and a corresponding member of the Medical Society, Dr. William Thornton (1761-1828), who besides practising medicine was also a skilful architect and built the most famous building in America, the Capitol and President's House in Washington.

In 1805 William Saunders, Astley Cooper, and others left the Society and formed a new medical and chirurgical society which later merged with other societies until in 1907 it became the Royal Society of Medicine.

The story of Lettsom's life and career has been well told, ${ }^{12}$ and his varied achievements clearly show what an exceptional man he was. An immense capacity for work, a sincere wish to help those in need, considerable skill in diagnosis, with a humane and practical approach to medical treatment, were linked with a readiness to question existing ideas. It was he who deserves much of the credit for letting the sunlight and fresh air into dark and insanitary houses, closed-in wards, and airless buildings. It was largely due to his efforts that the Sea-bathing Hospital at Margate was built in 1791. Treatment by sea bathing, especially after George III's visit to Weymouth, was becoming popular, and Lettsom was an enthusiastic supporter of the new fashion, making visits to his Margate hospital to see his sick-poor patients transported from London by sailing boats. He was concerned with the beginnings of the Royal Humane Society and new methods of resuscitation of the apparently drowned.

Postgraduate training has advanced so rapidly during the last two decades that it may well be asked whether there is still a place for such a society as the Medical Society of London in present-day conditions. To this there can be a clear answer that with the right aims and its present beautiful house in Chandos Street there surely is. The Society has wisely sent most of its valuable-and in some respects unique-library to the Wellcome Historical Library, where its rare books can be kept in ideal conditions, readily avail- 
able to research workers and others wishing to consult them with the help of skilled librarians. It has also wisely altered and redecorated its fine building in Chandos Street so that it now has really beautiful rooms, some catering, and excellent facilities for holding lectures and meetings for up to 150 persons. It fills an important need in the Harley Street area as a place where small groups can meet informally, socially, or in committees or discussion groups. Fellows of the society will be able to entertain their friends for small receptions or dinner parties. Its role as a forum to include all branches of the profession continues to be an important one, and its active council will surely be considering many plans for its future activities to ensure its keeping fully abreast of changing conditions. At present it numbers 500 Fellows and five honorary Fellows, among whom is the Duke of Edinburgh. Its old links with the Royal Society of Medicine are ideally joined in its bicentenary year by having Sir Hedley Atkins as its president during a year when he is also president of its daughter society, the Royal Society of Medicine.

I Abraham, J J., Lettsom. London, Heinemann Medical Books, 1933 Hunt, T. (ed.), The Medical Society of London 1773-1973. London. Heinemann Medical Books, 1972

\section{Irradiation of C.N.S. in Leukaemia}

The length of remissions and the survival of children with acute lymphoblastic leukaemia have improved considerably since the introduction of intensive intermittent combination chemotherapy. But as the remissions and the time of survival became longer, the frequency of leukaemia of the central nervous system (C.N.S.) increased to at least $50^{\prime \prime}$." in most series. ${ }^{1-3}$

C.N.S. leukaemia usually becomes overt at a time when there is no evidence of relapse elsewhere in the body, and it is reasonable to suggest that a C.N.S. relapse may in some way predispose to systemic relapse, since the latter usually closely follows a relapse in the central nervous system. D. Pinkel and his colleagues in Memphis, Tennessee, have shown that this complication can be prevented, with a resulting improvement in length of remission and survival.

Early attempts at preventing C.N.S. leukaemia consisted in giving 500 to 1,200 rads craniospinal irradiation early in remission, but these doses were found to be insufficient. ${ }^{245}$ In a subsequent study ${ }^{6}$ patients received 2,400 rads cranial irradiation plus intrathecal methotrexate five doses of 12 $\mathrm{mg} / \mathrm{m}^{2}$ ). This proved to be highly effective, and only 3 out of 31 children developed meningeal leukaemia. Eighteen of these 31 patients have been in continuous remission for $4 !$ to 5 years and have been off all treatment for $1 \frac{1}{2}$ to $2 \frac{1}{2}$ years. A further study showed that 2,400 rads craniospinal irradiation without intrathecal methotrexate was also effective, and C.N.S. leukaemia supervened in only two out of 45 irradiated patients compared with 33 out of 49 patients not irradiated. ${ }^{7}$ A more recent study from the same workers involved a randomized comparison of two groups of patients. One received craniospinal irradiation, the other cranial irradiation with five doses of intrathecal methotrexate. ${ }^{89}$ After cranial irradiation 2,400 rads) plus intrathecal metho- trexate three out of 45 patients developed C.N.S. leukaemia. After craniospinal irradiation (2,400 rads) two out of 49 patients developed C.N.S. leukaemia. Fifty-seven of the 94 patients remain in initial continuous complete remission for 8-28 months. To date this trial has therefore shown no difference between the two prophylactic regimens. Both forms of treatment of the central nervous system are associated with toxic effects and infection. As expected, leucopenia and subsequent sensitivity to chemotherapy are greater in the group receiving spinal irradiation, though the frequency of severe infection was the same in the two groups. However, the two fatalities during remission occurred in patients given craniospinal irradiation.

Analysis of patients receiving 500 rads, 1,200 rads, or no irradiation to the spine showed no difference in growth as long as six years after treatment, but the patients receiving 2,400 rads to the spine have not been followed up long enough after stopping chemotherapy to determine the ultimate effect on growth. From these studies it is now clear that, of the two methods of prophylaxis, cranial irradiation with intrathecal methotrexate is preferable to the potential retardation of growth, the longer treatment period, and the greater suppression of bone marrow with craniospinal irradiation. Recently the Medical Research Council has carried out a trial of the prophylaxis of C.N.S. leukaemia and two reports of its work appears at pages 381 and 385 of the British Medical fournal this week. The results confirm the findings of the Memphis Group. In this multicentre trial only one out of 75 patients who received prophylactic treatment of the central nervous system relapsed with meningeal leukaemia compared with 26 out of 80 patients not receiving prophylaxis. The prophylaxis entailed craniospinal irradiation (cranial 2,500 rads, spinal 1,000 rads) and 11 doses of intrathecal methotrexate $\left(10 \mathrm{mg} / \mathrm{m}^{2}\right)$. Unfortunately the patients were not randomized. Some centres submitted all their patients for prophylactic treatment, while other centres decided against giving any prophylaxis. Nevertheless, the difference between the two groups was so distinct that it outweighed any minor difference in management.

Undoubtedly the introduction of treatment of the central nervous system early in the disease has dramatically improved the survival of children with acute lymphoblastic leukaemia. Systemic relapse nearly always closely follows the development of symptoms in the central nervous system, and prophlylactic treatment to it prevents the systemic relapse as well as the symptoms. In both the American and the British studies the total relapse rate (C.N.S. and systemic) in the group receiving C.N.S. prophylaxis was approximately half that of the control group. Of the children who achieve remissions and are given modern multiple drug chemotherapy and irradiation of the C.N.S. more than $50 \%$ are expected to be alive and well after five years. And some of these are likely to be long survivors or even cured of their disease.

'Evans, A. E., Gilbert, E. S., and Sandstra, R., Cancer, 1970, 26, 404.

Pinkel, D., et al., Cancer, 1971, 27, 247.

West, R. J., Graham-Pole, J., Hardisty, R. M., and Pike, M. C., British Medical fournal, 1972, 3, 311.

George, P., et al., Fournal of Pediatrics, 1968, 72, 399.

Pinkel, D., Simone, J., Hustu, H. O., and Aur, R. J. A., Pediatrics, 1972, $50,246$.

A, et al, Blood 37,272

Aur, R. J. A., Simone, J. V., Hustu, H. O., and Verzosa, M. S., Cancer, $1972,29,381$.

Aur, R. J. A., Hustu, H. O., Verzosa, M. S., Wood, A., and Simone, J. V., Blood, 1973, in press.

Blood, 1973, in press.
Hustu, H. O., Aur, R. J. A., Verzosa, M. S., Simone, J. V., and Pinkel, D., Cancer, 1973, in press. 